July 2018

\title{
Aspirin in Primary Prevention of Myocardial Infarction/Angina and Stroke in Hypertensive Patients
}

\author{
Aysha Almas \\ Aga Khan University, aysha.almas@aku.edu \\ Muhammad Salman Ghazni \\ Tabba Heart Institute, Karachi. \\ Shahrukh Hashman \\ Aga Khan University \\ Zain Mushtaq \\ Aga Khan University, zain.mushtaq@aku.edu
}

Follow this and additional works at: https://ecommons.aku.edu/ pakistan_fhs_mc_med_intern_med

Part of the Cardiology Commons, and the Internal Medicine Commons

\section{Recommended Citation}

Almas, A., Ghazni, M. S., Hashman, S., Mushtaq, Z. (2018). Aspirin in Primary Prevention of Myocardial Infarction/Angina and Stroke in Hypertensive Patients. JCPSP: Journal of the College of Physicians and Surgeons--Pakistan..

Available at: https://ecommons.aku.edu/pakistan_fhs_mc_med_intern_med/36 


\section{Aspirin in Primary Prevention of Myocardial Infarction/Angina and Stroke in Hypertensive Patients}

Sir,

Hypertension is the leading attributable risk factor for mortality in the global burden of cardiovascular diseases (CVD). ${ }^{1}$ Role of aspirin has been under debate in the past decade. In contrast, in a recent systematic review published in 2015 on 103,787 patients, reported risk of major gastrointestinal bleeding was increased and risk of hemorrhagic stroke or other intracranial bleeding tended to be increased in primary prevention trials in patients on aspirin. ${ }^{2}$

In many large trials which were conducted, the use of aspirin and cardiovascular outcomes on South-Asian population was not represented although they are relatively at higher risk of CVD. ${ }^{3}$ Hence, aspirin use for prevention of CVD may have different results (both beneficial and adverse outcomes). So, the objective of this study is to determine the impact of aspirin use on cardiovascular disease including myocardial infarction (Ml/angina and stroke) in hypertensive patients.

We did a cross-sectional study conducted in the Department of Medicine, The Aga Khan University Hospital, Karachi, Pakistan over a 3-year period from 2010 to 2012. Ethical clearance was taken from the Ethics Review Committee of The Aga Khan University (2827-Med-ERC-13). All participants aged greater than 40 years with history of hypertension, admitted through emergency room with $\mathrm{Ml} /$ angina or stroke, were recruited. History of using aspirin was recorded. Hypertension was defined as SBP $>140 \mathrm{~mm} \mathrm{Hg}$ and DBP $>90 \mathrm{~mm} \mathrm{Hg.} 4$ Use of aspirin defined as using a minimum dose of $75-81 \mathrm{mg}$ of aspirin for minimum 4 weeks prior to ER visit was recorded.

A total of 575 patients were included in the study. Mean age was $63.96+11.67$ years, of which $372(64.7 \%)$ were males and $203(35 \%)$ were females. Aspirin use was present in $330(57.4 \%)$ patients. Out of the $343(59.7 \%)$ who had Ml/angina, 208/343 (60.6\%) were on aspirin for upto one month prior to the ER visit. Out of the 193 (33.6\%) stroke patients, 99/193 (51.3\%) were on aspirin. Upper gastrointestinal bleeding occurred in $49(8 \%)$ patients and $26(4.5 \%)$ were on aspirin. The OR of use of aspirin with myocardial infarction/angina and stroke is reported in Table I.

Use of aspirin did not show a clear benefit in primary prevention for ischemic heart diseases (IHD) and stroke in this hypertensive patient population. This concept has remained a topic of debate in the last decade. As use of aspirin in secondary prevention of IHD and stroke is well established in the high-risk prevalent atherosclerotic cardiovascular diseases including IHD and stroke, aspirin decreases acute CVD event (approximately 20\% reduction in coronary events and total stroke). ${ }^{5}$ This study demonstrated that there is no clear role of aspirin in primary prevention of IHD or stroke in hypertensive patients. Hence, we conclude that aspirin has no clear role in primary prevention of IHD or stroke in hypertensive patients; and this effect is irrespective of age and gender. However, more studies are required to further confirm this conclusion as this study has limited external validity.

\section{REFERENCES}

1. Lawes CM, Vander Hoorn S, Rodgers A, International Society of $\mathrm{H}$. Global burden of blood-pressure-related disease, 2001. Lancet 2008; 371:1513-8.

2. Whitlock EP, Williams SB, Burda BU, Feightner A, Beil T. Aspirin use in adults: cancer, all-cause mortality, and harms: A systematic evidence review for the U.S. preventive services task force. Rockville (MD); 2015.

3. Jafar TH, Chaturvedi N, Gul A, Khan AQ, Schmid CH, Levey AS. Ethnic differences and determinants of proteinuria among South Asian subgroups in Pakistan. Kidney Int; 64:1437-44.

4. Chobanian AV, Bakris GL, Black HR. Seventh report of the joint national committee on prevention, detection, evaluation, and treatment of high blood pressure. Hypertension 42:1206-52.

5. Collaborative overview of randomised trials of antiplatelet therapy--III: Reduction in venous thrombosis and pulmonary embolism by antiplatelet prophylaxis among surgical and medical patients. Antiplatelet Trialists' Collaboration. BMJ 1994; 308:235-46.

Aysha Almas ${ }^{1}$, Muhammad Salman Ghazni², Shahrukh Hashmani ${ }^{3}$ and Zain Mushtaq ${ }^{1}$

1 Department of Internal Medicine, The Aga Khan University Hospital, Karachi.

2 Department of Adult Cardiology, Tabba Heart Institute, Karachi.

3 Department of Adult Cardiology, The Aga Khan University Hospital, Karachi.

Correspondence: Dr. Aysha Almas, Associate Professor, Department of Internal Medicine, The Aga Khan University Hospital, Stadium Road, Karachi.

E-mail:aysha.almas@aku.edu

Received: June 07, 2017; Accepted: March 06, 2018.

Table I: Association of aspirin use with ischemic heart disease and stroke adjusted for covariates.

\begin{tabular}{|c|c|c|c|c|c|c|}
\hline Aspirin used N (\%) & Crude OR 95\% Cl & $p$-value & $\begin{array}{c}\text { Adjusted model * } \\
\text { OR } 95 \% \mathrm{Cl}\end{array}$ & $p$-value & $\begin{array}{c}\text { Adjusted Model }^{* *} \\
\text { OR } 95 \% \mathrm{Cl}\end{array}$ & $\mathrm{p}$-value \\
\hline \multirow{2}{*}{$208(60.6)$} & \multicolumn{5}{|c|}{ Ischemic heart disease $(\mathrm{N}=343)$} & \\
\hline & $0.76(0.5,1.0)$ & 0.06 & $0.72(0.5,1.0)$ & 0.06 & $0.8(0.51,1.2)$ & 0.3 \\
\hline \multirow[t]{2}{*}{$99(51.3)$} & & & Stroke $(\mathrm{N}=193)$ & & & \\
\hline & $0.69(0.49,0.9)$ & 0.04 & $0.7(0.49,1.0)$ & 0.7 & $0.7(0.5,1.1)$ & 0.2 \\
\hline
\end{tabular}
..... 5 ..... 